\title{
Retrospective and Prospective Human Intravenous and Oral Pharmacokinetic Projection of Dipeptidyl peptidase-IV Inhibitors Using Simple Allometric Principles - Case Studies of ABT-279, ABT-341, Alogliptin, Carmegliptin, Sitagliptin and Vildagliptin
}

\author{
Ravindranath R Gilibili ${ }^{1}$, Ravi Kanth Bhamidipati ${ }^{2}$, Ramesh Mullangi ${ }^{2}$, and Nuggehally R Srinivas ${ }^{3}$ \\ ${ }^{1}$ Faculty of Pharmaceutical Sciences, University of British Columbia, Vancouver, Canada; ${ }^{2}$ Drug Metabolism and \\ Pharmacokinetics, Jubilant Biosys Ltd, Industrial Suburb, Yeshwanthpur, Bangalore, India; ${ }^{3}$ DRILS, Gachibowli, \\ Hyderabad, India.
}

Received, February 14, 2015; Revised, September 4, 2015; Accepted, September 10, 2015; Published, September 15, 2015.

\begin{abstract}
Purpose: The purpose of this exercise was to explore the utility of allometric scaling approach for the prediction of intravenous and oral pharmacokinetics of six dipeptidy peptidase-IV (DPP-IV) inhibitors viz. ABT-279, ABT-341, alogliptin, carmegliptin, sitagliptin and vildagliptin. Methods: The availability of intravenous and oral pharmacokinetic data in animals enabled the allometry scaling of 6 DPP-IV inhibitors. The relationship between the main pharmacokinetic parameters [viz. volume of distribution $\left(\mathrm{V}_{\mathrm{d}}\right)$ and clearance $(\mathrm{CL})$ ] and body weight was studied across three or four mammalian species, using double logarithmic plots to predict the human pharmacokinetic parameters of $\mathrm{CL}$ and $\mathrm{V}_{\mathrm{d}}$ using simple allometry. Results: A simply allometry relationship: $\mathrm{Y}=\mathrm{aW}^{\mathrm{b}}$ was found to be adequate for the prediction of intravenous and oral human clearance/volume of distribution for DPP-IV inhibitors. The allometric equations for alogliptin, carmegliptin, sitagliptin, vildagliptin, ABT-279 and ABT-341 were $1.867 \mathrm{~W}^{0.780}, 1.170 \mathrm{~W}^{0.756}, 2.020 \mathrm{~W}^{0.529}, 1.959 \mathrm{~W}^{0.847}, 0.672$ $\mathrm{W}^{1.016}, 1.077 \mathrm{~W}^{0.649}$, respectively, to predict intravenous clearance $(\mathrm{CL})$ and the corresponding equations to predict intravenous volume of distribution $\left(\mathrm{V}_{\mathrm{d}}\right)$ were: $3.313 \mathrm{~W}^{0.987}, 6.096 \mathrm{~W}^{0.992}, 7.140 \mathrm{~W}^{0.805}, 2.742 \mathrm{~W}^{0.941}$, $1.299 \mathrm{~W}^{0.695}$ and $5.370 \mathrm{~W}^{0.803}$. With the exception of a few discordant values the exponent rule appeared to hold for CL (0.75) and $V_{d}(1.0)$ for the predictions of various DPP-IV inhibitors. Regardless of the routes, the predicted values were within 2-3 fold of observed values and intravenous allometry was better than oral allometry. Conclusion: Simple allometry retrospectively predicted with reasonable accuracy the human reported values of gliptins and could be used as a prospective tool for this class of drugs.
\end{abstract}

This article is open to POST-PUBLICATION REVIEW. Registered readers (see "For Readers") may comment by clicking on ABSTRACT on the issue's contents page.

\section{INTRODUCTION}

It is well understood that gut endocrine cells play an important role in the release of incretin hormones such as glucagon-like peptide (GLP-1) and glucose dependent insulinotropic polypeptide (GIP) (1). The release of both GLP-1 and GIP is triggered by the food intake and once these incretin hormones are released, amongst other things they play a major role in maintaining glucose homeostasis by the release of insulin. However, both GLP-1 and GIP are subject to rapid degradation in vivo by the enzyme dipeptidyl peptidase-IV (DPP-IV), present in a soluble form in the blood circulation (2). Due to immediate action of DPP-IV, the pharmacological activities of both GLP-1 and GIP are short lived and typically exhibit relatively short half-lives in the circulation $(3,4)$. Since the pharmacology and importance of GLP-1 and GIP is now well understood, inclusive of formation and inactivation of the hormones, strategically two options have been explored to improve the therapeutic benefit of these incretin hormones. First therapeutic option comprises of the use of incretin mimetics, which are analogs of GLP-1 but are resistant to the hydrolytic cleavage exerted by DPPIV enzymes. The second therapeutic option comprises of the use of DPP-IV inhibitors which inactivate the circulating DPP-IV enzyme so that

Corresponding Author: Nuggehally R Srinivas, Adjunct Professor, DRILS, Gachibowli, Hyderabad, India; E-mail: srini.suramus@yahoo.com 
these enzymes cannot interfere with the physiological role of incretin hormones as such rendering longer term benefits in maintaining glucose homeostasis $(5,6)$.

The introduction of allometry concept to predict the human pharmacokinetic parameters using relevant pharmacokinetic data from animal species was due to the pioneering work of Boxenbaum and co-workers $(7,8)$. While there is an ongoing debate on the use of predictive tools in vitro or in vivo inclusive of allometry and other scaling techniques, it is needless to say that allometry has withstood the test of time for over several decades now. One of the premises the allometry predictions rely is on the scalability of the physiological functions for the excretion/elimination of the drug as a function of body weight in mammalian species. Hence if the drug undergoes elimination without metabolism or limited metabolism, it may be ideally suited for simple scaling approaches using allometry. However, the differential metabolism and/or transport related elimination across species may tend to provide erroneous predictions by using simple allometry. Hence, the use of correction factors has been proposed and in many instances has led to closer predictions of the pharmacokinetic data. It is important to note that Bonata and Howard (9) criticized the use of allometry for the dose selection for the first-in human trial and it was suggested that allometry may provide false sense of security and the chosen acceptance criteria were not<smiles>Cn1c(=O)cc(N2CCC[C@@H](N)C2)n(Cc2ccccc2C#N)c1=O</smiles>

stringent for data interpretation. In contrast, Mahmood (2009) reported the prospective dose selection for the first-in-human dose trial for a monoclonal antibody (10). Furthermore, Mahmood (2009) clarified the importance of correction factors that may further render allometry as a balanced predictive tool (10). Srinivas (2010) has reviewed several case studies of allometry work from the published literature and provided balanced perspectives on the utility of allometry (11). In addition, to scientific challenges and optimization of the experimental designs for better allometry predictions, Srinivas (2010) has provided insights on how to effectively use allometry for clinical candidate selection and answer some early drug development questions (11).

Review of the literature suggested that with the exception of saxagliptin (12), reports on allometry scaling of other gliptins have not been published or readily available. In our analysis, we have taken two groups of gliptins - one where both the human intravenous (i.v) and oral pharmacokinetic data are available [namely: sitagliptin (13), vildagliptin (14); Figure 1a] or only human oral pharmacokinetic data is available [alogliptin (15); Figure 1a] and the other where the human i.v and oral pharmacokinetic data are not available (namely: ABT-279, ABT341, carmegliptin; Figure 1b). Using allometry principle, we have predicted the human pharmacokinetics for both groups of gliptins.

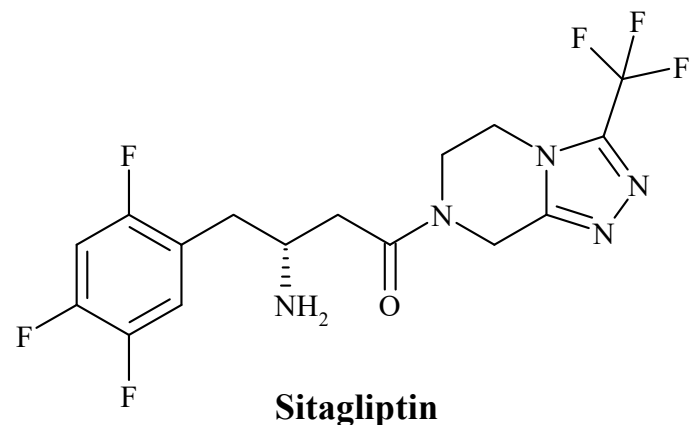

Alogliptin

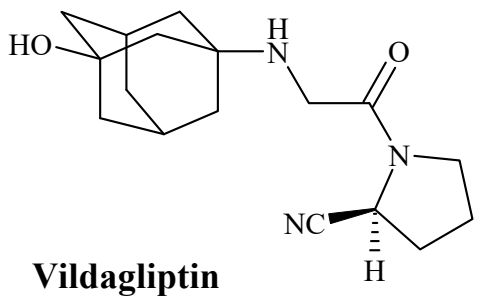

Figure 1a. Structural representation of alogliptin, sitagliptin and vildagliptin 


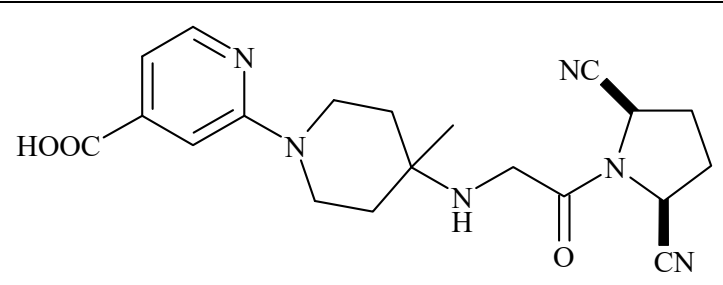

ABT-279<smiles>N[C@@H]1CC(C(=O)N2CCn3c(nnc3C(F)(F)F)C2)CCC1c1cc(F)c(F)cc1F</smiles>

ABT-341<smiles>COc1cc2c(cc1OC)[C@H]1C[C@H](N)[C@@H](N3C[C@H](CF)CC3=O)CN1CC2</smiles>

Figure 1b. Structural representation of ABT-279, ABT-341 and carmegliptin

\section{METHODS}

\section{Data compilation and parameters calculation}

We used PubMed ${ }^{\circledR}$ (NCBI 2015) database to find relevant articles to aid in the allometry scaling exercise. The key words used in the search included gliptins, preclinical, and pharmacokinetics. Only gliptins that had published pharmacokinetic data either after oral or i.v dosing in at least 3 animal species were considered for allometry predictions. The observed human pharmacokinetic data for the relevant gliptins were also gathered in order to enable the comparison of the predicted vs observed pharmacokinetic data. Following the literature search, the following gliptins: ABT-279 (16), ABT341 (17), alogliptin (18), carmegliptin (19), sitagliptin $(20,21)$ and vildagliptin $(14,22)$ were considered for the analysis. For all the DPP-IV inhibitors, pharmacokinetic data from three preclinical species viz., rat, dog and monkey were available. From the reported publications, demographic, dosing and pharmacokinetic data were obtained for the various preclinical species. The data compilation included number of animals, body weight of animals $(\mathrm{Kg})$, dose administered $(\mathrm{mg} / \mathrm{Kg})$, AUC $(\mu \mathrm{g} \cdot \mathrm{h} / \mathrm{mL}), \mathrm{t}_{1 / 2}(\mathrm{~h}), \mathrm{K}_{\mathrm{el}}\left(\mathrm{h}^{-1}\right), \mathrm{CL}$ $(\mathrm{mL} / \mathrm{h} / \mathrm{Kg})$ and $\mathrm{F}(\%)$. The $\mathrm{V}_{\mathrm{d}}(\mathrm{L} / \mathrm{Kg})$ values were calculated by using equation $\mathrm{V}_{\mathrm{d}}=\mathrm{CL} / \mathrm{K}_{\mathrm{el}}$. For any data if mean and standard deviation values were reported, the mean value was used in calculations. If a range of values was provided in the literature, the average of the two extreme values was used. The oral and i.v data for various DPP-IV inhibitors obtained from the different preclinical species are compiled in Tables 1 and 2, respectively.

\section{Allometric scaling}

Simple allometry was performed using the relationship:

$$
\mathrm{Y}=\mathrm{aW}
$$

Where $\mathrm{Y}$ is the respective parameter, ' $\mathrm{a}$ ' is coefficient, ' $\mathrm{b}$ ' is exponent and $\mathrm{W}$ is weight $(\mathrm{Kg})$. Pharmacokinetic parameters, $\mathrm{CL}$ and $\mathrm{V}_{\mathrm{d}}$ obtained from each species were plotted against respective body weight on a $\log$ to $\log$ scale. A regression analysis was performed using Microsoft Excel 2010 (Microsoft software, Seattle, USA).

The ' $a$ ' and ' $b$ ' values obtained from the regression analyses were included in the allometric equations and a human body weight of $70 \mathrm{Kg}$ was considered for the scaling purposes. Along with the regression coefficient, the significance of the correlation was tested at a significance (p-value) level of 0.05 using a freely available web-based statistical software (Social Science Statistics) (23). 
Table 1. Oral pharmacokinetic parameters of DPP-IV inhibitors in various preclinical species

\begin{tabular}{|c|c|c|c|c|c|c|c|c|c|}
\hline Compound & $\begin{array}{c}\text { Species } \\
\text { (number) }\end{array}$ & $\begin{array}{c}\text { Average body } \\
\text { weight }(\mathrm{Kg})\end{array}$ & $\begin{array}{c}\text { Dose } \\
(\mathrm{mg} / \mathrm{Kg})\end{array}$ & $\begin{array}{c}\text { AUC } \\
\text { (ng.h/mL) }\end{array}$ & $\begin{array}{l}\mathrm{t}_{1 / 2} \\
(\mathrm{~h})\end{array}$ & $\begin{array}{l}\text { Kel } \\
\left(\mathrm{h}^{-1}\right) \\
\end{array}$ & $\begin{array}{c}\mathrm{CL} / \mathrm{F} \\
(\mathrm{mL} / \mathrm{h} / \mathrm{Kg})\end{array}$ & $\begin{array}{c}\mathrm{V}_{\mathrm{d}} / \mathrm{F} \\
(\mathrm{L} / \mathrm{Kg})\end{array}$ & $\begin{array}{c}\mathrm{F} \\
(\%)\end{array}$ \\
\hline \multirow{3}{*}{ Alogliptin ${ }^{(18)}$} & Rat $(n=3)$ & 0.27 & 10 & 1240 & 2.8 & 0.24 & 8065 & 8.80 & 45 \\
\hline & $\operatorname{Dog}(n=3)$ & 9.00 & 3.0 & 950 & 1.5 & 0.46 & 3158 & 61.5 & 86 \\
\hline & $\begin{array}{l}\text { Monkey } \\
(n=4)\end{array}$ & 4.60 & 2.0 & 2331 & 7.0 & 0.09 & 858 & 39.9 & 72 \\
\hline \multirow{4}{*}{ Carmegliptin $^{(19)}$} & Rat $(n=3)$ & 0.43 & 1.0 & 220 & 9.7 & 0.07 & 4545 & 27.5 & 32 \\
\hline & $\operatorname{Dog}(n=3)$ & 11.5 & 2.5 & 3330 & 12 & 0.05 & 751 & 144 & 110 \\
\hline & $\begin{array}{l}\text { Monkey } \\
(\mathrm{n}=2)\end{array}$ & 9.90 & 3.0 & 1840 & 11 & 0.06 & 1630 & 263 & 31 \\
\hline & Rat $(n=3)$ & 0.40 & 2.0 & 489 & 2.3 & 0.30 & 4090 & 5.49 & 81 \\
\hline \multirow{2}{*}{ Sitagliptin $^{(20)}$} & $\operatorname{Dog}(n=3)$ & 12.0 & 0.4 & 653 & 4.1 & 0.16 & 613 & 43.2 & 84 \\
\hline & $\begin{array}{l}\text { Monkey } \\
(n=2)\end{array}$ & 6.00 & 2.0 & 814 & 3.7 & 0.18 & 2457 & 78.6 & 96 \\
\hline \multirow{5}{*}{ Vildagliptin ${ }^{(22)}$} & Mouse (NA) & 0.03 & NA & 3500 & 1.5 & 0.46 & 3723 & 0.06 & 94 \\
\hline & Rat (NA) & 0.25 & NA & 2400 & 8.8 & 0.07 & 5333 & 3.33 & 45 \\
\hline & Rabbit (NA) & 3.00 & NA & 1600 & 6.8 & 0.10 & 2388 & 8.96 & 67 \\
\hline & Dog (NA) & 9.00 & NA & 1300 & 0.89 & 0.77 & 1300 & 16.9 & 100 \\
\hline & Monkey (NA) & 6.00 & NA & 1400 & 0.84 & 0.82 & 1505 & 19.4 & 93 \\
\hline \multirow{3}{*}{ ABT-279 $9^{(16)}$} & Rat $(n=6)$ & 0.25 & 5.0 & 2100 & 4.7 & 0.14 & 2381 & 4.04 & 28 \\
\hline & $\operatorname{Dog}(n=6)$ & 9.00 & 2.5 & 970 & 5.3 & 0.13 & 2577 & 177 & 35 \\
\hline & $\begin{array}{l}\text { Monkey } \\
(\mathrm{n}=6)\end{array}$ & 6.00 & 2.5 & 580 & 2.0 & 0.34 & 4310 & 74.6 & 11 \\
\hline \multirow{3}{*}{ ABT-341 ${ }^{(17)}$} & Rat $(n=6)$ & 0.25 & 5.0 & 1948 & 5.4 & 0.12 & 2567 & 5.00 & 67 \\
\hline & $\operatorname{Dog}(n=6)$ & 9.00 & 2.5 & 6285 & 6.7 & 0.10 & 398 & 34.6 & 104 \\
\hline & $\begin{array}{l}\text { Monkey } \\
(n=6)\end{array}$ & 6.00 & 2.5 & 1905 & 6.3 & 0.11 & 1312 & 71.6 & 54 \\
\hline
\end{tabular}

NA: Not available

\section{RESULTS}

\section{Alogliptin}

Figure 2 upper panel shows the simple allometric plots $\left(1.867 \mathrm{~W}^{0.780}\right.$ for i.v and $3.925 \mathrm{~W}^{0.578}$ for oral) for the prediction of human CL value from the available three preclinical species viz., rat, dog and monkey. The close scrutiny of the exponent values suggested that the value was in close proximity of 0.75 (within 22\%), which is recommended for a good fit and prediction of value on a body weight basis. Similarly, the Figure 2 lower panel illustrates the simple allometric plots $\left(3.313 \mathrm{~W}^{0.987}\right.$ for i.v and $17.90 \mathrm{~W}^{0.548}$ for oral) for the prediction of human $V_{d}$ from the three preclinical species data. The correlation between the $\mathrm{V}_{\mathrm{d}}$ and body weight appeared to be satisfactory for the i.v route since the exponent was very close to proposed exponent value of 1.0 (Table 3). However, the exponent obtained for the oral route appeared to be discordant. 
Table 2. Intravenous pharmacokinetic parameters of DPP-IV inhibitors in various preclinical species

\begin{tabular}{|c|c|c|c|c|c|c|c|}
\hline Compound & $\begin{array}{c}\text { Species } \\
\text { (number) }\end{array}$ & $\begin{array}{l}\text { Average body } \\
\text { weight }(\mathrm{Kg})\end{array}$ & $\begin{array}{c}\text { Dose } \\
(\mathrm{mg} / \mathrm{Kg})\end{array}$ & $\begin{array}{l}\mathrm{t}_{1 / 2} \\
(\mathrm{~h})\end{array}$ & $\begin{array}{l}\text { Kel } \\
\left(\mathrm{h}^{-1}\right)\end{array}$ & $\begin{array}{c}\mathrm{CL} \\
(\mathrm{mL} / \mathrm{h} / \mathrm{Kg})\end{array}$ & $\begin{array}{c}\mathrm{V}_{\mathrm{d}} \\
(\mathrm{L} / \mathrm{Kg})\end{array}$ \\
\hline \multirow{3}{*}{ Alogliptin ${ }^{(18)}$} & Rat $(n=3)$ & 0.27 & 1.0 & 1.40 & 0.49 & 2972 & 0.95 \\
\hline & $\operatorname{Dog}(n=3)$ & 9.00 & 1.0 & 1.50 & 0.46 & 2435 & 34.7 \\
\hline & Monkey $(\mathrm{n}=4)$ & 4.60 & 1.0 & 5.70 & 0.12 & 529 & 12.0 \\
\hline \multirow{3}{*}{ Carmegliptin $^{(19)}$} & Rat $(n=3)$ & 0.43 & 1.0 & 5.32 & 0.13 & 1452 & 2.73 \\
\hline & $\operatorname{Dog}(n=3)$ & 11.5 & 1.0 & 13.2 & 0.05 & 840 & 120 \\
\hline & Monkey $(n=2)$ & 9.90 & 1.0 & 6.80 & 0.10 & 508 & 32.9 \\
\hline \multirow{3}{*}{ Sitagliptin $^{(20)}$} & Rat $(n=3)$ & 0.25 & 1.0 & 1.70 & 0.40 & 3600 & 2.19 \\
\hline & $\operatorname{Dog}(n=3)$ & 9.00 & 1.0 & 4.90 & 0.14 & 360 & 22.7 \\
\hline & Monkey $(\mathrm{n}=2)$ & 6.00 & 1.0 & 3.70 & 0.18 & 1680 & 53.4 \\
\hline \multirow{5}{*}{ Vildagliptin $^{(22)}$} & Mouse (NA) & 0.03 & NA & 1.50 & 0.46 & 3500 & 0.06 \\
\hline & Rat (NA) & 0.25 & NA & 8.80 & 0.07 & 2400 & 1.50 \\
\hline & Rabbit (NA) & 3.00 & NA & 6.80 & 0.10 & 1600 & 6.00 \\
\hline & $\operatorname{Dog}(\mathrm{NA})$ & 9.00 & NA & 0.89 & 0.77 & 1300 & 16.8 \\
\hline & Monkey (NA) & 6.00 & NA & 0.84 & 0.82 & 1400 & 18.0 \\
\hline \multirow{3}{*}{ ABT-279 ${ }^{(16)}$} & Rat $(n=6)$ & 0.25 & 5.0 & 6.80 & 0.10 & 680 & 0.55 \\
\hline & $\operatorname{Dog}(n=6)$ & 9.00 & 2.5 & 6.40 & 0.10 & 910 & 13.5 \\
\hline & Monkey $(n=6)$ & 6.00 & 2.5 & 1.70 & 0.40 & 510 & 1.80 \\
\hline \multirow{3}{*}{ ABT-341 ${ }^{(17)}$} & Rat $(n=6)$ & 0.25 & 5.0 & 5.30 & 0.13 & 1712 & 1.80 \\
\hline & $\operatorname{Dog}(n=6)$ & 9.00 & 2.5 & 7.00 & 0.09 & 415 & 36.3 \\
\hline & Monkey $(n=6)$ & 6.00 & 2.5 & 4.30 & 0.16 & 703 & 19.2 \\
\hline
\end{tabular}

\section{Carmegliptin}

Figure 3 upper panel shows the simple allometric plots $\left(1.170 \mathrm{~W}^{0.756}\right.$ for i.v and $3.175 \mathrm{~W}^{0.551}$ for oral) for the prediction of human CL value from the available three preclinical species viz., rat, dog and monkey. Though the oral exponent value was not matching with suggested exponent value of 0.75 , the i.v exponent values was in close agreement with the suggested value of 0.75 . Similarly, the Figure 3 lower panel depicts the simple allometric plots $\left(6.096 \mathrm{~W}^{0.992}\right.$ for i.v and $46.25 \mathrm{~W}^{0.604}$ for oral) for the prediction of human $\mathrm{V}_{\mathrm{d}}$ from the three preclinical species data. The correlation between the $\mathrm{V}_{\mathrm{d}}$ and body weight appeared to be satisfactory since the exponent varied within $33 \%$ to the proposed exponent value of 1.0 (Table 3 ).

\section{Sitagliptin}

Figure 4 upper panel shows the simple allometric plots $\left(2.020 \mathrm{~W}^{0.529}\right.$ for i.v and $3.568 \mathrm{~W}^{0.523}$ for oral) for the prediction of human CL value from the available three preclinical species viz., rat, dog and monkey. Similarly, the Figure 4 lower panel illustrates the simple allometric plots $\left(7.140 \mathrm{~W}^{0.805}\right.$ for i.v and $14.76 \mathrm{~W}^{0.675}$ for oral) for the prediction of human $\mathrm{V}_{\mathrm{d}}$ from the three preclinical species data. The correlation between the $V_{d}$ and body weight appeared to be satisfactory since the exponent was within $33 \%$ when compared to the proposed exponent value of 1.0 (Table 3 ). Though the exponent values obtained for oral $\mathrm{CL}$ and $\mathrm{V}_{\mathrm{d}}$ following simple allometric scaling prediction were not very close unlike the i.v exponent values, the predicted $\mathrm{CL}$ and $\mathrm{V}_{\mathrm{d}}$ for both oral and i.v routes were found to match with the reported human CL and $V_{d}$ values (Table 4). 


\section{$\underline{\text { Alogliptin }}$}

IV

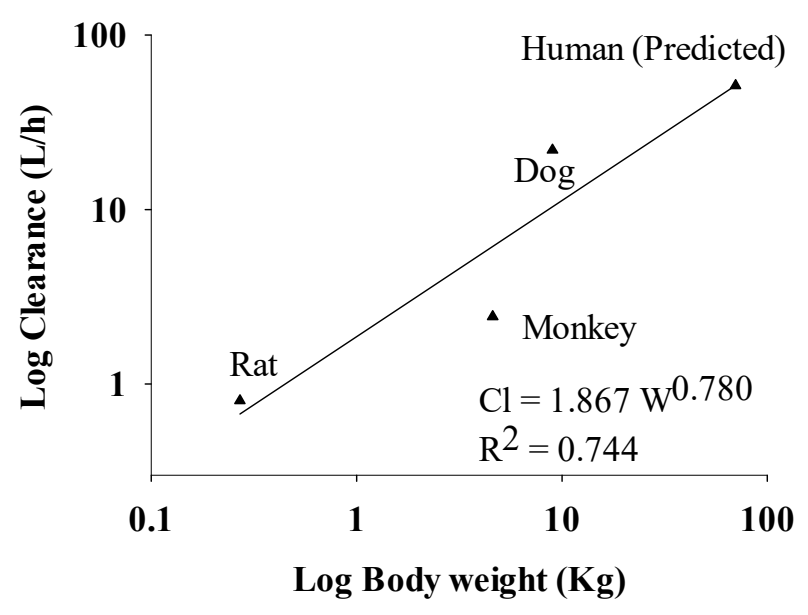

IV

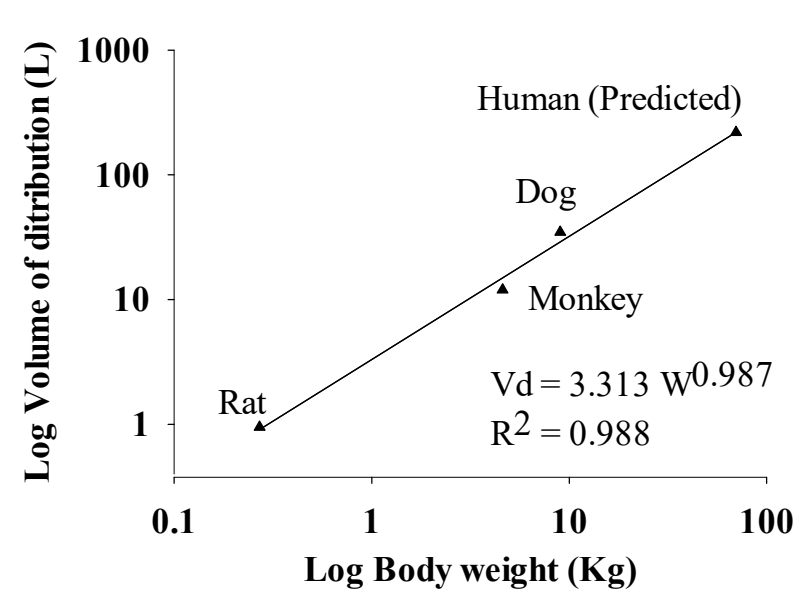

Oral

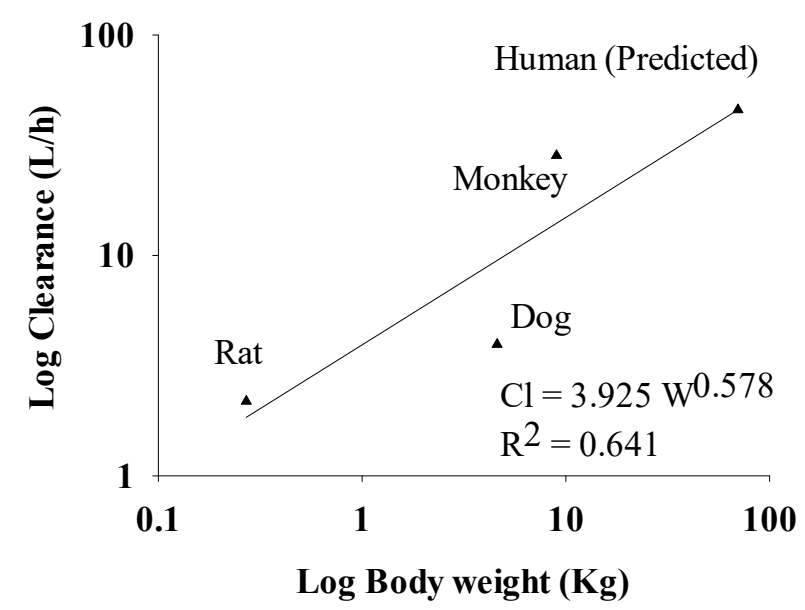

Oral

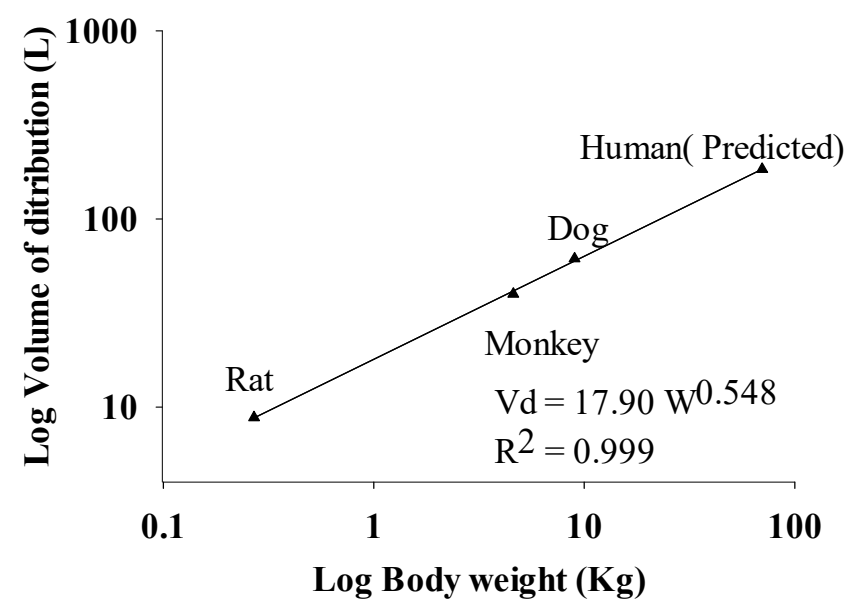

Figure 2. Simple allometric scaling for prediction of human clearance (upper panel) and volume of distribution (lower panel) for alogliptin using rat, dog and monkey

\section{Vildagliptin}

Figure 5 upper panel shows the simple allometric plots $\left(1.959 \mathrm{~W}^{0.847}\right.$ for i.v and $3.465 \mathrm{~W}^{0.809}$ for oral) for the prediction of human CL value from the available five preclinical species viz., mouse, rat, rabbit, dog and monkey. The correlation between the CL and body weight appeared to be satisfactory since the exponent was very close (within 13\%) to the proposed exponent value of 0.75 (Table 3). Similarly, the Figure 5 lower panel illustrates the simple allometric plots $\left(2.742 \mathrm{~W}^{0.941}\right.$ for i.v and
$3.581 \mathrm{~W}^{0.910}$ for oral) for the prediction of human $\mathrm{V}_{\mathrm{d}}$ from the five preclinical species data. The correlation between the $\mathrm{V}_{\mathrm{d}}$ and body weight appeared to be satisfactory since the exponent was very close to proposed exponent value of 1.0 (Table 3). The availability of data from five preclinical species helped to predict human $\mathrm{V}_{\mathrm{d}}$ and CL for both oral and i.v routes and the predicted oral (i.e. CL/F) value matched with the reported value in humans (Table 4). 


\section{Carmegliptin}
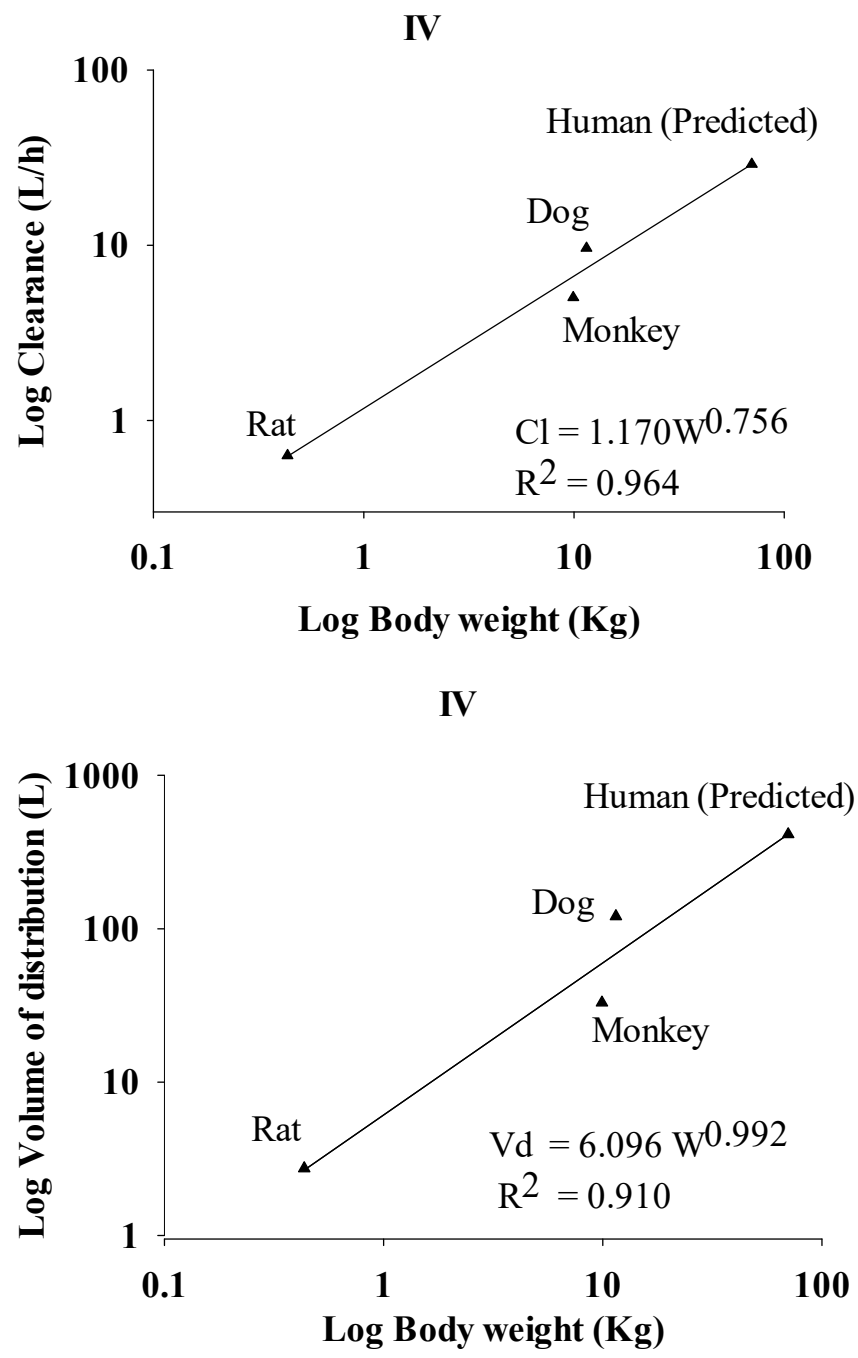
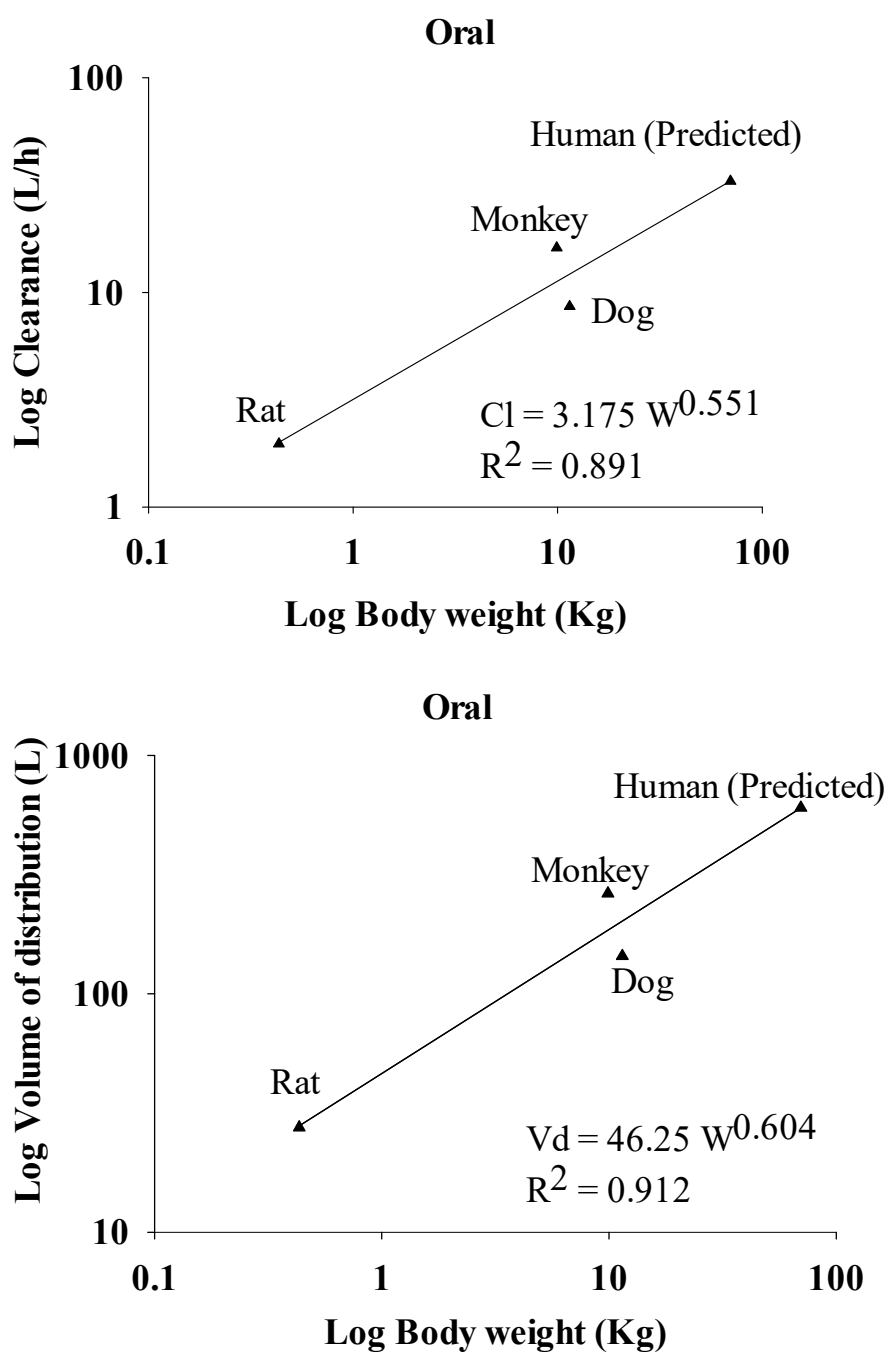

Figure 3. Simple allometric scaling for prediction of human clearance (upper panel) and volume of distribution (lower panel) for carmegliptin using rat, dog and monkey

\section{ABT-279}

Figure 6 upper panel shows the simple allometric plots $\left(0.672 \mathrm{~W}^{1.016}\right.$ for i.v and $3.233 \mathrm{~W}^{1.085}$ for oral $)$ for the prediction of human $C L$ value from the available three preclinical species viz., rat, dog and monkey. The close scrutiny of the exponent values suggested that the value was within $27 \%$ of the proposed exponent value of 0.75 , which is recommended for a good fit and prediction the human parameter value. Similarly, the Figure 6 lower panel illustrates the simple allometric plots $\left(1.299 \mathrm{~W}^{0.695}\right.$ for i.v and $15.78 \mathrm{~W}^{1.003}$ for oral) for the prediction of human $\mathrm{V}_{\mathrm{d}}$ from the three preclinical species data. The correlation between the $\mathrm{V}_{\mathrm{d}}$ and body weight appeared to be satisfactory since the exponent was within $31 \%$ as compared to the proposed exponent value of 1.0 (Table 3 ). 


\section{Sitagliptin}

IV

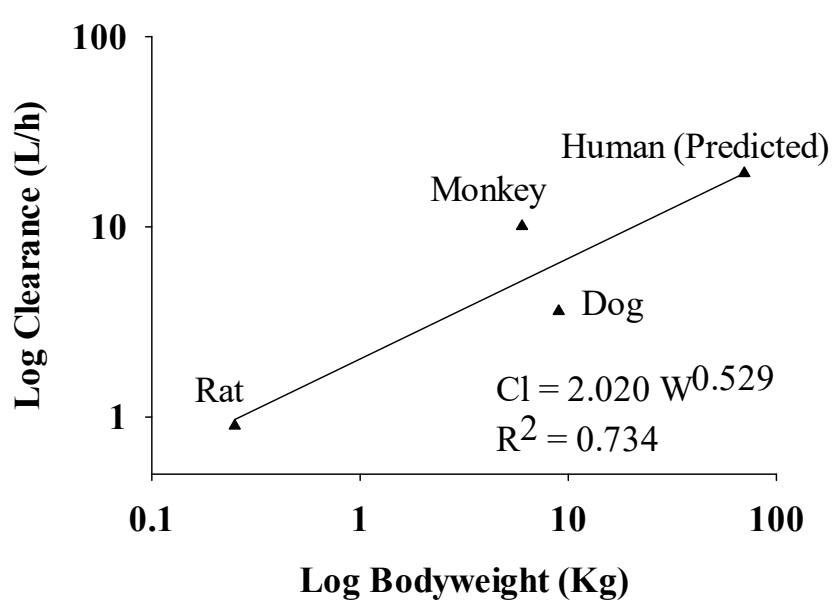

IV

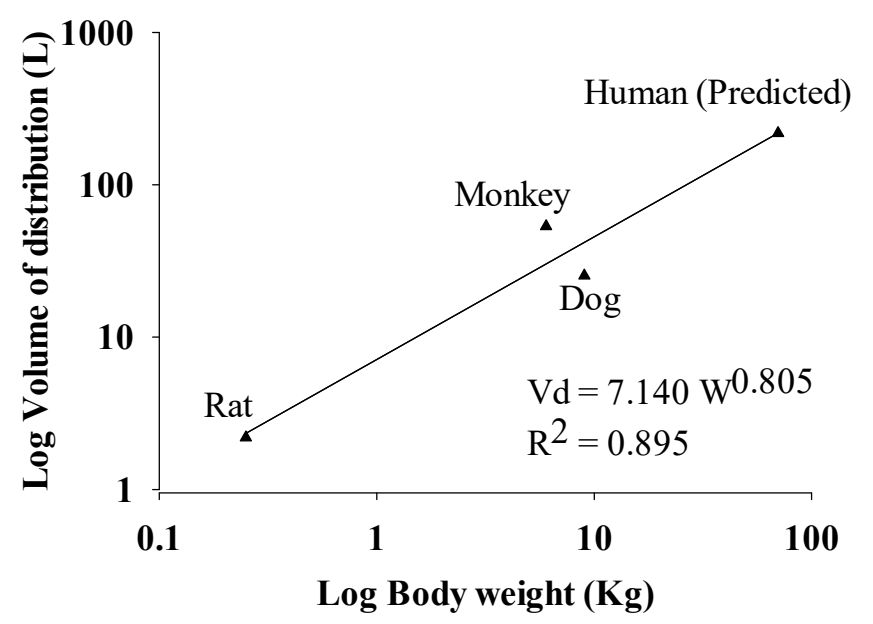

Oral

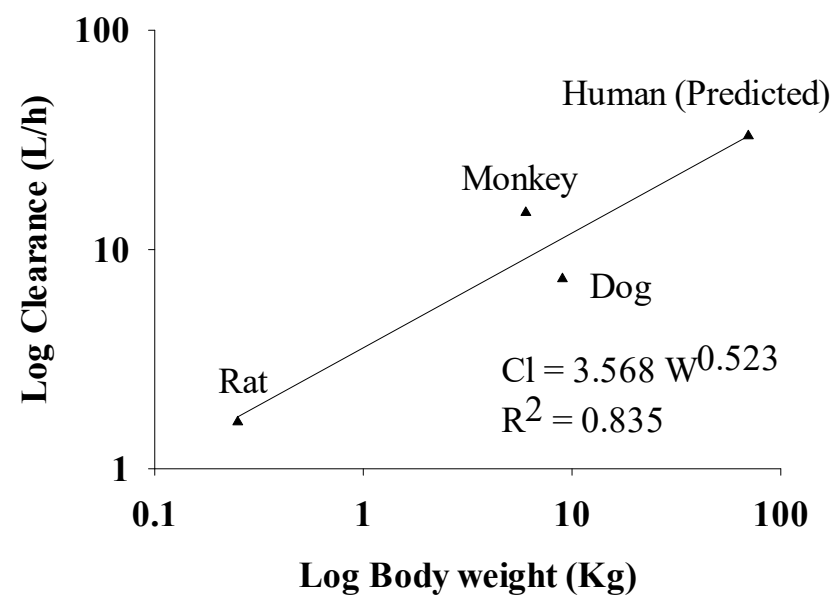

Oral

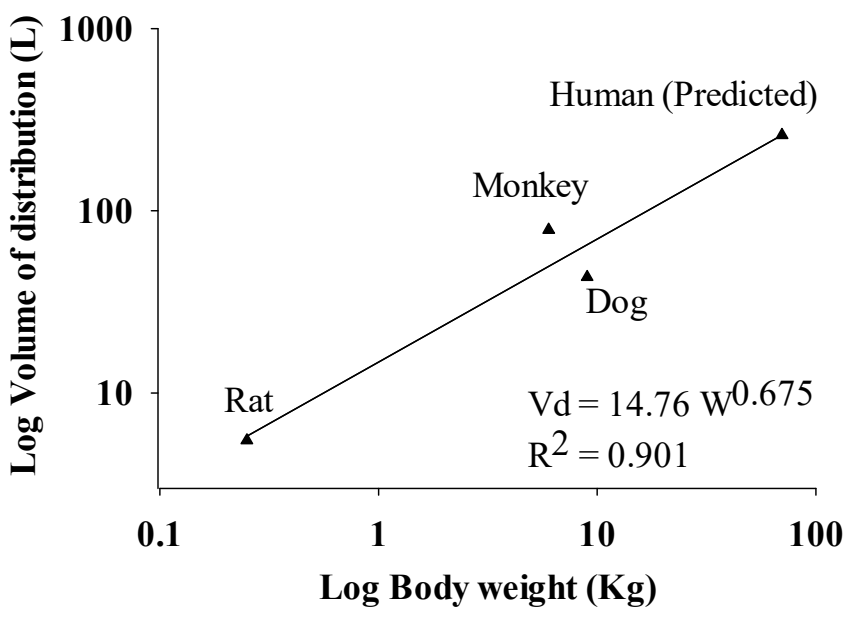

Figure 4. Simple allometric scaling for prediction of human clearance (upper panel) and volume of distribution (lower panel) for sitagliptin using rat, dog and monkey

\section{ABT-341}

Figure 7 upper panel shows the simple allometric plots $\left(1.077 \mathrm{~W}^{0.649}\right.$ for i.v and $2.768 \mathrm{~W}^{0.598}$ for oral $)$ for the prediction of human CL value from the available three preclinical species viz., rat, dog and monkey. The close scrutiny of the exponent values suggested that the value was in close proximity of 0.75 (within 18\%), which is recommended for a good fit and prediction of the human parameter value. Similarly, the Figure 7 lower panel illustrates the simple allometric plots $\left(5.370 \mathrm{~W}^{0.803}\right.$ for i.v and $13.13 \mathrm{~W}^{0.653}$ for oral) for the prediction of human $V_{d}$ from the three preclinical species data. The correlation between the $V_{d}$ and body weight appeared to be satisfactory since the exponent was within $35 \%$ to the proposed exponent value of 1.0 (Table 3).

\section{DISCUSSION}

The chosen gliptins in this work represent marketed drugs or compounds undergoing preclinical/ clinical development. 


\section{Vildagliptin}

IV

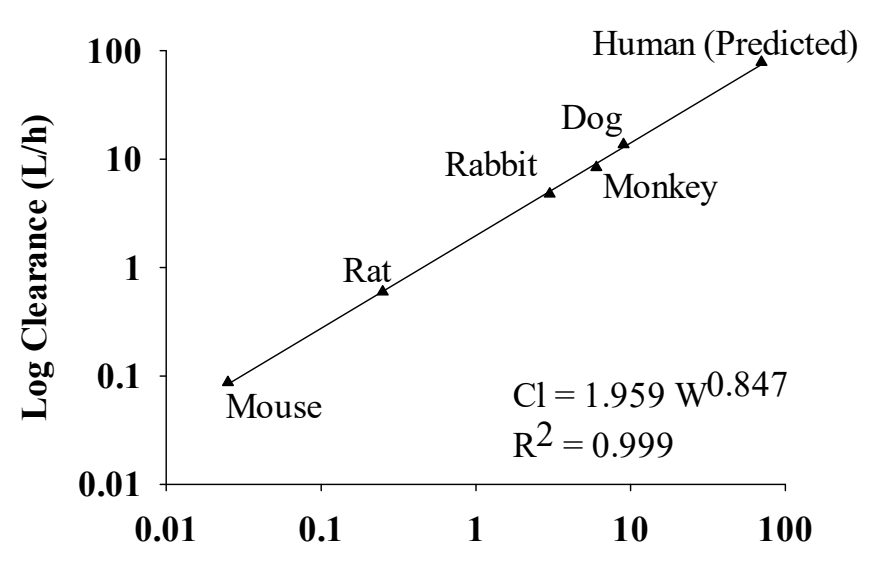

Log Bodyweight (Kg)

IV

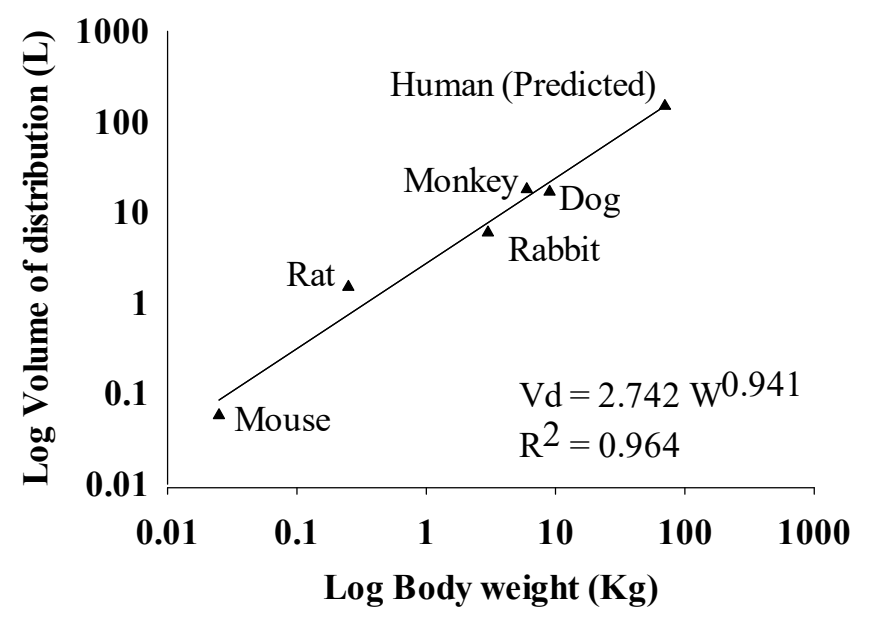

Oral
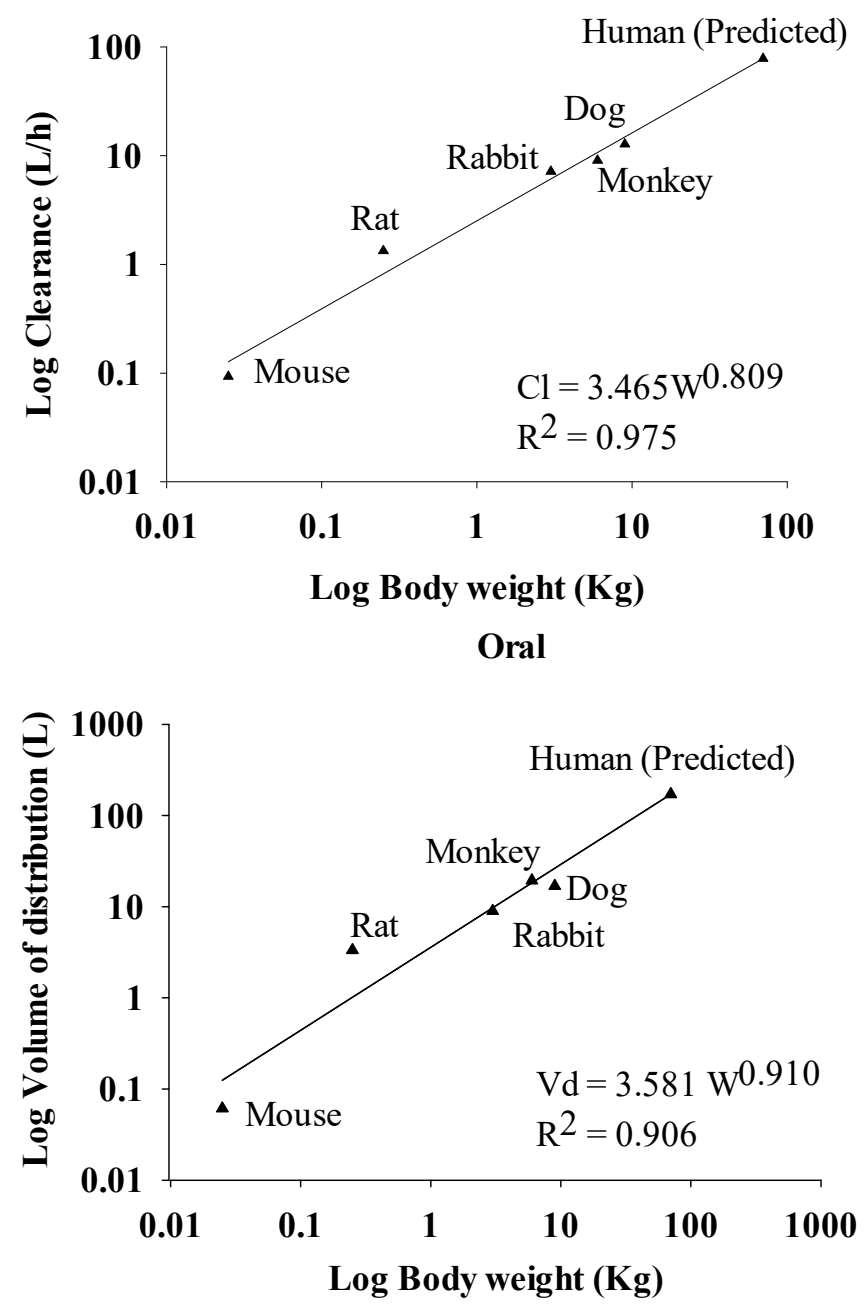

Figure 5. Simple allometric scaling for prediction of human clearance (upper panel) and volume of distribution (lower panel) for vildagliptin using mouse, rat, rabbit, dog and monkey

The collected list represents interesting structural analogs showing varying degree of DPP-IV inhibitory potencies and selectivity differences for other DPP inhibitions. These compounds in addition provide diverse pharmacokinetic disposition characteristics, mass balance and biotransformation attributes adding complexity for the use of a simple prediction tool such as allometry. A recent review describes the pharmacodynamics and clinical pharmacology aspects of several approved gliptins used in our present analysis (24). The elimination half-life values varies from approximately $1.5-4 \quad \mathrm{~h}$ (vildagliptin) to almost $21 \mathrm{~h}$ (alogliptin) suggesting that it may be important to select the ideal gliptin to support either once-a-day or twice-a-day administration of the gliptin in the diabetic patients. Depending on the type of gliptin, the unchanged drug excreted in the urine varies - for example while $80 \%$ of the renally excreted radioactivity accounts for the unchanged sitagliptin, only $22 \%$ of the renally excreted radioactivity accounts for the unchanged vildagliptin. 


\section{ABT-279}

IV
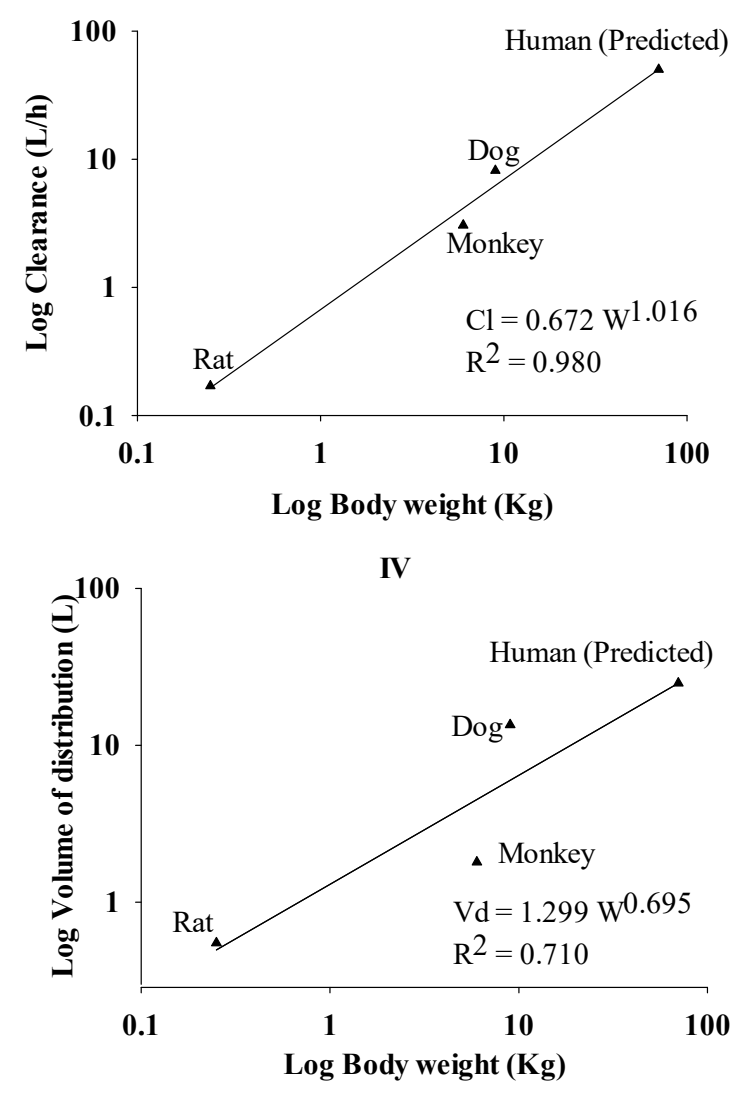

Oral
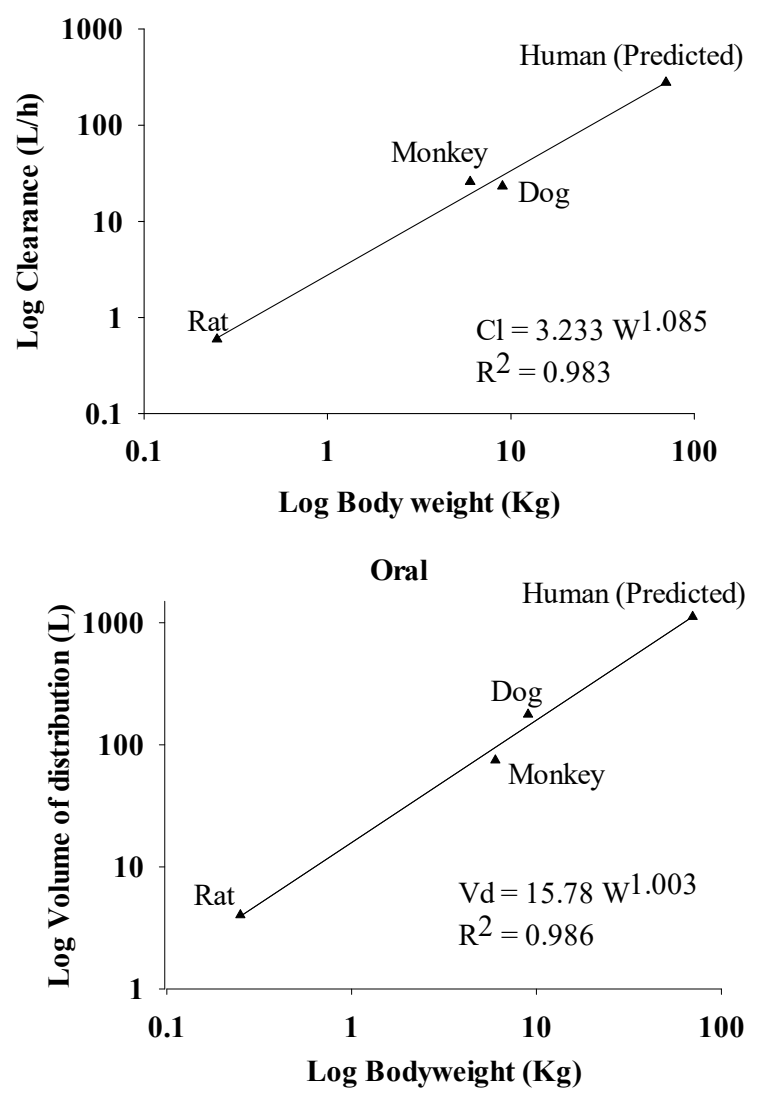

Figure 6. Simple allometric scaling for prediction of human clearance (upper panel) and volume of distribution (lower panel) for ABT-279 using rat, dog and monkey

In terms of metabolic fate, gliptins differ in the extent of metabolism - for instance saxagliptin has been reported to undergo more metabolism including formation of an active metabolite as compared to alogliptin. With the exception of linagliptin which shows relatively higher protein binding $(75-99 \%)$, the protein binding of other marketed gliptins such as sitagliptin (38\%), alogliptin (20\%), saxagliptin $(<10 \%)$ and vildagliptin $(9 \%)$ are low and clinically inconsequential for pharmacodynamic activity (24).

Overall, we believe that the various case studies of gliptins in this work present the right balance of compounds to carefully scrutinize the application of allometry from both retrospective and prospective human pharmacokinetic predictions within the same class of compounds. It should be noted that we had three gliptins that had published human pharmacokinetic data (alogliptin, sitagliptin and vildagliptin) and three others where human pharmacokinetic data were not available or reported (ABT-279, ABT-341 and carmegliptin). We did not include saxagliptin in our case studies since previously human pharmacokinetic predictions were reported using allometry (12).

Based on allometric equations and prediction values it appeared that application of simple allometry was more than satisfactory in predicting human pharmacokinetic values of gliptins in a retrospective manner. The predicted i.v pharmacokinetic data were somewhat closer to observed values, as compared to the predicted oral pharmacokinetic data; however, generally the 


\section{ABT-341}

IV
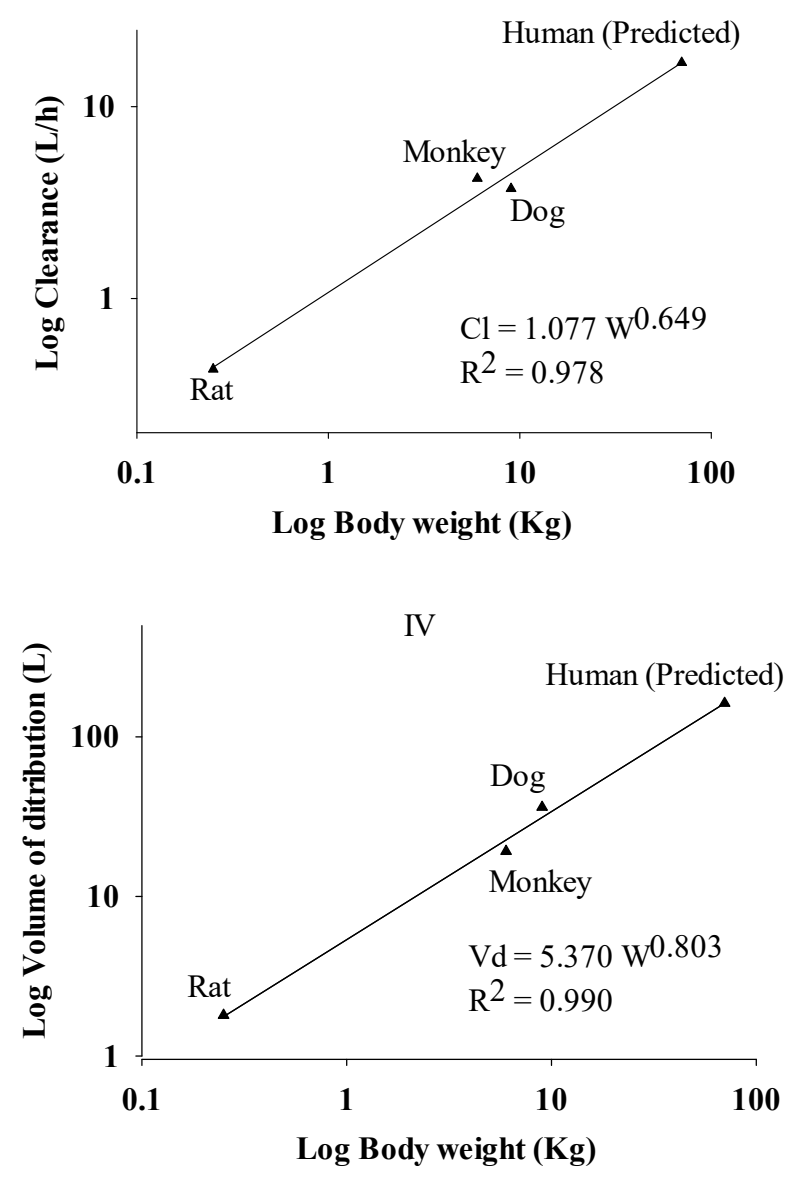

Oral
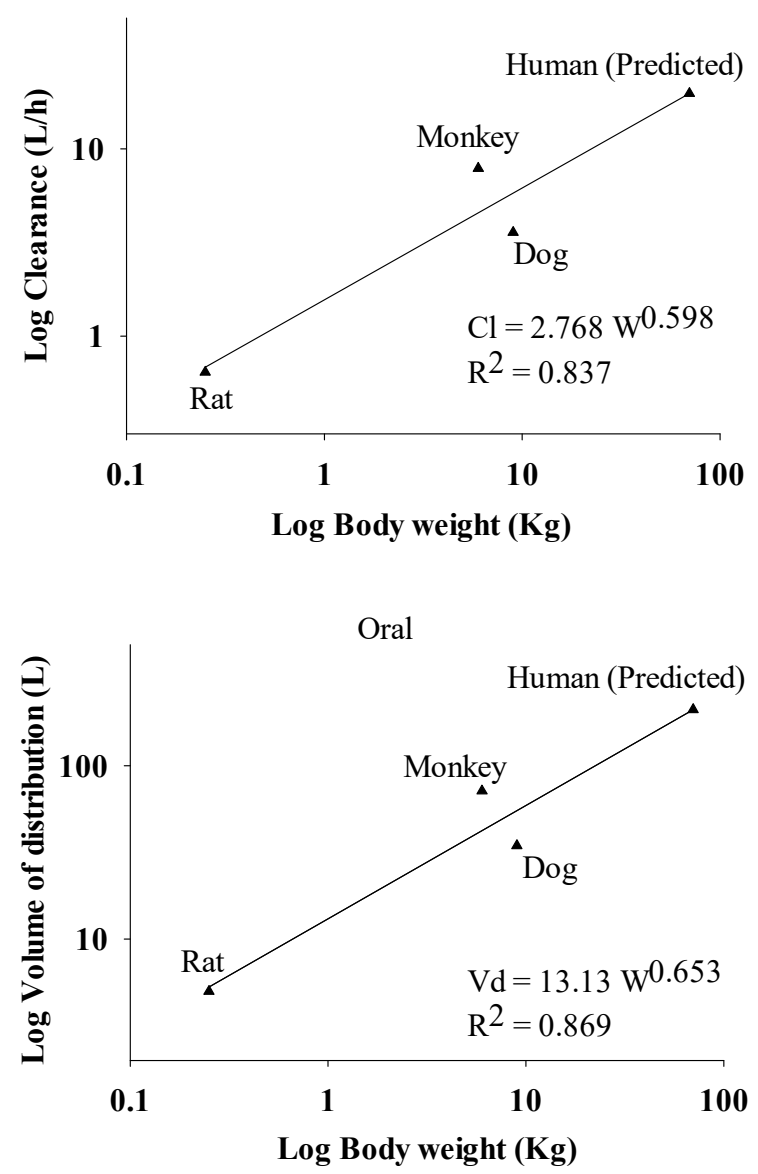

Figure 7. Simple allometric scaling for prediction of human clearance (upper panel) and volume of distribution (lower panel) for ABT-341 using rat, dog and monkey

predicted values regardless of the routes of administration were within 2-fold of the observed values. Recent publications have suggested that allometry predictions within 2-fold prediction error may be useful in establishing human relevant values $(25,26)$. Hence, application of allometry tool is feasible and could be considered for prospective prediction of both i.v and oral pharmacokinetic data for newer analogs of gliptins. This is in contrast to the interpretation of the allometry scaling data for saxagliptin, where it was reported that both human clearance and volume of distribution would be under predicted using allometry approach (25). Interestingly, the allometric exponent values of clearance and volume for saxagliptin were 0.35 and
0.66 , respectively, were considerably lower than the corresponding exponent values of either clearance (average value: 0.73 ) or volume (average value: 0.80 ) terms in the present work for all the gliptins. It should be emphasized that saxagliptin unlike other gliptins undergoes significant hepatic metabolism accounting for almost $51 \%$ of the administered dose given orally, while sitagliptin showed modest hepatic metabolism (about 21\%); alogliptin and vildagliptin showed low hepatic metabolism (about 10\%) and linagliptin displayed negligible hepatic metabolism (about 2\%) (24).

Inspection of data in Table 4 suggested that the predicted clearance values between i.v and oral routes were similar for all gliptins, with the 
exception of sitagliptin and ABT-279 where the oral clearance was greater by 1.7 -fold and 5.4-fold when compared to i.v clearance. Interestingly, the disparity in the observed oral clearance of sitagliptin may be explained because sitagliptin undergoes some degree of hepatic metabolism via CYP3A4/5 isozymes and leads to formation of oxidative metabolites that get excreted through biliary or renal pathway. There is no published data available on ABT-279 for further scrutiny. In the other extreme, we examined the predicted vs observed clearance for alogliptin which has a somewhat lower metabolism as compared to that of sitagliptin. It appeared that alogliptin which undergoes lesser metabolism in its first pass provided a better predictability of its oral clearance as compared to sitagliptin.

Interestingly, it appeared that the predictions of gliptins after i.v route of administration may be superior to that of the oral route as exemplified by the data from sitagliptin. The i.v route of drug administration provides $100 \%$ bioavailability of the drug discounting any lung related metabolism if relevant. Since the pharmacokinetic parameters are scaled using the body weight and the physiological factors that affect species dependent elimination /distribution of the drug, generally the predictability of the scaling is not compromised after the i.v drug administration. On the other hand, after the oral route of drug administration, except in a few instances where the bioavailability may tend to be high and equaling $100 \%$, the oral bioavailability of drugs vary across species. There are number of factors that may contribute to the differential oral bioavailability of the drug after oral route of dosing. Most notably, both drug solubility and permeability may impede the oral absorption. In addition, presystemic metabolism via CYP enzymes, efflux transport, narrow window for drug absorption, instability of the drug during the gastrointestinal transit may all contribute for the varied bioavailability. Because of all of the above factors inclusive of differences in metabolism and transport amongst the preclinical species, the allometry predictions for the oral route of drug administration need to be additionally scrutinized to avoid any misleading information.

Since approved gliptins and the others in development are used in oral dosage forms, these observations for sitagliptin and ABT-279 suggest that one has to use caution in computing oral clearance value for pediatric age group (especially in juvenile diabetic patients) as there is a tendency to administer a large quantum of dose for such gliptins. In this context, the recent work of Mahmood (2010) provides an opportunity to scale and predict the clearance values of various gliptins in children (27). In this interesting work, it was shown that use of maximum life span potential (MLP) correction with an empirical factor was a better approach than simple allometry to predict the clearance value in the pediatric age group (27). A quick inspection of exponents of various gliptins that were subject to simple allometry in our work suggested that with the exception of couple of cases the exponent values for allometry equations for clearance exceeded 0.75 and hence, simple allometry approach to predict the clearance in children would have not resulted in accurate dosing strategy. Interestingly, inspection of the predicted i.v data for all six gliptins indicated that they fell under two distinct categories if considered for use in pediatric age groups: (a) high clearance group of 14.5 to $16.6 \mathrm{~mL} / \mathrm{min} / \mathrm{Kg}$ comprising ABT-279, alopgliptin and vildagliptin and (b) low clearance group of 4.88 to $7.62 \mathrm{~mL} / \mathrm{min} / \mathrm{Kg}$ consisting of sitagliptin, ABT-341 and carmegliptin. Hence, a common strategy could be developed for the two distinct groups of gliptins from a pediatric drug administration point of view.

In summary, a simple allometry approach was found to be feasible for the prediction of the human pharmacokinetics of various gliptins. Based on the close proximity of the predicted values to the observed values consideration may be given for the prospective use of simple allometry for the prediction of newer analogs of gliptins.

\section{REFERENCES}

1. Drucker DJ. The role of gut hormones in glucose homeostasis. J Clin Invest. 2007; 117: 24-32.

2. Lambeir AM, Durinx C, Scharpe S, De Meester I. Dipeptidyl-peptidase IV from bench to bedside: an update on structural properties, functions, and clinical aspects of the enzyme DPP IV. Crit Rev Clin Lab Sci. 2003; 40: 209-94.

3. Mentlein R, Gallwitz B, Schmidt WE. Dipeptidylpeptidase IV hydrolyses gastric inhibitory polypeptide, glucagon-like peptide-1 (7-36 amide), and peptide histidine methionine and is responsible for their degradation in human serum. Eur $\mathrm{J}$ Biochem. 1993; 214: 829-835.

4. Gault VA, Parker JC, Harriott P, Flatt PR, O'Harte FP. Evidence that the major degradation product 
of glucose-dependent insulinotropic polypeptide, GIP(3-42), is a GIP receptor antagonist in vivo. J Endocrinol. 2002; 175: 525-533.

5. Mest HJ, Mentlein R. Dipeptidyl peptidase inhibitors as new drugs for the treatment of type 2 diabetes. Diabetologia 2005; 48: 616-620.

6. Drucker DJ, Nauck MA. The incretin system: glucagon-like peptide-1 receptor agonists and dipeptidyl peptidase- 4 inhibitors in type 2 diabetes. Lancet 2006; 368: 1696-1705.

7. Boxenbaum H. Interspecies scaling, physiological time and the ground plan of pharmacokinetics. J Pharmacokinet Biopharm. 1982; 10: 201-227

8. Boxenbaum H, Fertug JB. Scaling of antipyrine intrinsic clearance of unbound drug in 15 mammalian species. Eur J Drug Metab Pharmacokinet. 1984; 9: 177-183.

9. Bonate PL, Howard D. Prospective allometric scaling: does the emperor have clothes? J Clin Pharmacol. 2000; 40: 665-670.

10. Mahmood I. Pharmacokinetic allometric scaling of antibodies: application to the first-in-human dose estimation. J Pharm Sci. 2009; 98: 3850-3861.

11. Srinivas NR. Allometry as a tool in drug development: case studies, perspectives and general considerations, pp 47 - 106. In Drug Development Perspectives - considerations, challenges and strategies, edited by N.R. Srinivas, HNB Publishing, New York, 2010.

12. Fura A, Khanna A, Vyas V, Koplowitz B, Chang SY, Caporuscio C, et al. Pharmacokinetics of the dipeptidyl peptidase 4 inhibitor saxagliptin in rats, dogs, and monkeys and clinical projections. Drug Metab Dispos. 2009; 37: 1164-1171.

13. Bergman A, Ebel, Liu F, Stone J, Wang A, Zeng W, et al. Absolute bioavailability of sitagliptin, an oral dipeptidyl peptidase-4 inhibitor, in healthy volunteers. Biopharm Drug Dispos. 2007; 28: 315 322.

14. Australian Public Assessment Report for Vildagliptin. 2010 (www.tga.gov.au/pdf/auspar/ auspar-galvus.pdf).

15. Christopher R, Covington P, Davenport M, Fleck P, Mekki QA, Wann ER, et al. Pharmacokinetics, pharmacodynamics, and tolerability of single increasing doses of the dipeptidyl peptidase-4 inhibitor alogliptin in healthy male subjects. Clin Ther. 2008; 30:513-527.

16. Madar DJ, Kopecka H, Pireh D, Yong H, Pei Z, Li $X$, et al. Discovery of 2-[4- $\{\{2-(2 S, 5 R)-2-c y a n o-5-$ ethynyl-1-pyrrolidinyl]-2-oxoethyl]amino]-4-

methyl-1-piperi- dinyl]-4-pyridinecarboxylic Acid (ABT-279): A very potent, selective, effective, and well-tolerated inhibitor of dipeptidyl peptidase-IV, useful for the treatment of diabetes. J Med Chem. 2006; 49: 6416-6420.
17. Pei Z, Li X, von Geldern TW, Madar DJ, Longenecker K, Yong H, et al. Discovery of ( ( 4 R , $5 \mathrm{~S})$ - 5-amino - 4 - ( 2, 4, 5-trifluorophenyl ) cyclohex-1-enyl)-(3-(trifluoromethyl)-5,6- dihydro$[1,2,4]$ triazolo [ 4, 3 - a]pyrazine - 7 ( $8 \mathrm{H})-\mathrm{y}$ 1 ) methanone (ABT-341), a highly potent, selective, orally efficacious, and safe dipeptidyl peptidase IV inhibitor for the treatment of type 2 diabetes. J Med Chem. 2006; 49: 6439-6442.

18. Lee B, Shi L, Kassel DB, Asakawa T, Takeuchi K, Christopher RJ. Pharmacokinetic, pharmacodynamic, and efficacy profiles of alogliptin, a novel inhibitor of dipeptidyl peptidase4, in rats, dogs and monkeys. Eur J Pharmacol. 2008; 589: 306-314.

19. Kuhlmann O, Paehler A, Weick I, Funk C, Pantze M, Zell M, et al. Pharmacokinetics and metabolism of the dipeptidylpeptidase IV inhibitor carmeglitptin in rats, dogs and monkeys. Xenobiotica 2010; 40: 840-852.

20. Kim D, Wang L, Beconi M, Eiermann GJ, Fisher $\mathrm{MH}, \mathrm{He} \mathrm{H}$, et al. (2R)-4-oxo-4-[3-(trifluoromethyl)5,6-dihydro [1,2,4]triazolo [4,3-a]pyrazin-7(8H)-yl]1-(2,4,5-trifluoro-phenyl) butan-2-amine: a potent, orally active dipeptidyl peptidase IV inhibitor for the treatment of type 2 diabetes. J Med Chem. 2005; 48: 141-151.

21. Beconi MG, Reed JR, Teffera Y, Xia YQ, Kochansky CJ, Liu DQ, et al. Disposition of the dipeptidyl peptidase 4 inhibitor sitagliptin in rats and dogs. Drug Metab Dispos. 2007; 35: 525-532.

22. He H, Tran P, Yin H, Smith H, Flood D, Kramp R, et al. Disposition of vildagliptin, a novel dipeptidyl peptidase 4 inhibitor, in rats and dogs. Drug Metab Dispos. 2009; 37: 545-554.

23. http://www.socscistatistics.com/pvalues/pearsondistr ibution.aspx

24. Golightly LK, Drayna CC, McDermott MT. Comparative clinical pharmacokinetics of dipeptidyl peptidase-4 inhibitors. Clin Pharmacokinet. 2012; 51: 501-514.

25. Sinha VK, Vaarties K, De Buck SS, Fenu LA, Nijsen M, Gilissen RA, et al. Towards a better prediction of peak concentration, volume of distribution and half-life after oral drug administration in man, using allometry. Clin Pharmacokinet. 2011; 50: 307-318.

26. Paine SW, Ménochet K, Denton R, McGinnity DF, Riley RJ. Prediction of human renal clearance from preclinical species for a diverse set of drugs that exhibit both active secretion and net reabsorption. Drug Metab Dispos. 2011; 39: 1008-1013.

27. Mahmood I. Interspecies scaling for the prediction of drug clearance in children: application of maximum lifespan potential and an empirical correction factor. Clin Pharmacokinet. 2010; 49: 479-492. 
Table 3. Allometric equations derived for various DPP-IV inhibitors

\begin{tabular}{|c|c|c|c|c|c|c|c|c|c|c|c|c|}
\hline \multirow[b]{2}{*}{ Compound } & \multicolumn{6}{|c|}{ Oral } & \multicolumn{6}{|c|}{ Intravenous } \\
\hline & $\mathrm{CL}$ & $\mathrm{r}^{2}$ & $\mathrm{p}$ & $\mathrm{V}_{\mathrm{d}}$ & $\mathrm{r}^{2}$ & $\mathrm{p}$ & $\mathrm{CL}$ & $\mathrm{r}^{2}$ & $\mathrm{p}$ & $\mathrm{V}_{\mathrm{d}}$ & $\mathrm{r}^{2}$ & $\mathrm{p}$ \\
\hline Alogliptin & $3.925 \mathrm{~W}^{0.578}$ & 0.641 & 0.046 & $17.90 \mathrm{~W}^{0.548}$ & 0.999 & $<0.00001$ & $1.867 \mathrm{~W}^{0.780}$ & 0.744 & 0.009 & $3.313 \mathrm{~W}^{0.987}$ & 0.988 & $<0.00001$ \\
\hline Carmegliptin & $3.175 \mathrm{~W}^{0.551}$ & 0.891 & 0.003 & $46.25 \mathrm{~W}^{0.604}$ & 0.912 & 0.002 & $1.170 \mathrm{~W}^{0.756}$ & 0.964 & 0.0001 & $6.096 \mathrm{~W}^{0.992}$ & 0.910 & 0.002 \\
\hline Sitagliptin & $3.568 \mathrm{~W}^{0.523}$ & 0.835 & 0.0099 & $14.76 \mathrm{~W}^{0.675}$ & 0.901 & 0.002 & $2.020 \mathrm{~W}^{0.529}$ & 0.734 & 0.038 & $7.140 \mathrm{~W}^{0.805}$ & 0.895 & 0.0026 \\
\hline Vildagliptin & $3.465 \mathrm{~W}^{0.809}$ & 0.975 & $<0.00001$ & $3.581 \mathrm{~W}^{0.910}$ & 0.906 & 0.000764 & $1.959 \mathrm{~W}^{0.847}$ & 0.999 & $<0.00001$ & $2.742 \mathrm{~W}^{0.941}$ & 0.964 & 0.000028 \\
\hline ABT-279 & $3.233 \mathrm{~W}^{1.085}$ & 0.983 & $<0.00001$ & $15.78 \mathrm{~W}^{1.003}$ & 0.986 & $<0.00001$ & $0.672 \mathrm{~W}^{1.016}$ & 0.980 & $<0.00001$ & $1.299 \mathrm{~W}^{0.695}$ & 0.710 & 0.00096 \\
\hline ABT-341 & $2.768 \mathrm{~W}^{0.598}$ & 0.837 & $<0.00001$ & $13.13 \mathrm{~W}^{0.653}$ & 0.869 & $<0.00001$ & $1.077 \mathrm{~W}^{0.649}$ & 0.978 & $<0.00001$ & $5.370 \mathrm{~W}^{0.803}$ & 0.990 & $<0.00001$ \\
\hline
\end{tabular}

${ }^{\#} \mathrm{p}$ value determined assuming $\mathrm{n}=3$

Table 4. Predicted and reported $V_{d}$ and CL values for various DPP-IV inhibitors

\begin{tabular}{|c|c|c|c|c|c|c|c|c|}
\hline \multirow{2}{*}{ Compound } & \multicolumn{4}{|c|}{ Oral } & \multicolumn{4}{|c|}{ Intravenous } \\
\hline & \multicolumn{2}{|c|}{$\mathrm{CL} / \mathrm{F} \quad(\mathrm{mL} / \mathrm{h} / \mathrm{Kg})$} & \multicolumn{2}{|c|}{$\mathrm{V}_{\mathrm{d}} / \mathrm{F}(\mathrm{L} / \mathrm{Kg})$} & \multicolumn{2}{|c|}{$\mathrm{CL}(\mathrm{mL} / \mathrm{h} / \mathrm{Kg})$} & \multicolumn{2}{|c|}{$\mathrm{V}_{\mathrm{d}}(\mathrm{L} / \mathrm{Kg})$} \\
\hline & Predicted & Reported & Predicted & Reported & Predicted & Reported & Predicted & Reported \\
\hline Alogliptin & 654 & 249 & 2.63 & 6.06 & 732 & NA & 3.14 & NA \\
\hline Carmegliptin & 470 & NA & 3.72 & NA & 273 & NA & 3.12 & NA \\
\hline Sitagliptin & 1122 & 708 & 2.44 & 1.18 & 1020 & 600 & 1.08 & 1.00 \\
\hline Vildagliptin & 471 & 670 & 8.60 & NA & 415 & NA & 5.90 & NA \\
\hline ABT-279 & 3972 & NA & 16.0 & NA & 720 & NA & 0.36 & NA \\
\hline ABT-341 & 283 & NA & 3.01 & NA & 242 & NA & 2.32 & NA \\
\hline Saxagliptin $^{(12)}$ & 306 & 1044 & NA & NA & 204 & NA & NA & NA \\
\hline
\end{tabular}


